\section{Psicopatologia fenomenológica contemporânea}

Guilherme Peres Messas. São Paulo: Roca; 2008. 248p. ISBN

978-85-7241-777-8.

Em um momento em que parte da psiquiatria mundial começa a questionar os rumos que nosso sistema nosográfico vem tomando ${ }^{1,2}$, o livro editado por Guilherme P. Messas é atual. Não é (e não se propõe a ser) um tratado de psicopatologia. Na verdade, deste detalhe talvez decorra um dos principais méritos do livro: não se ocupa da infrutífera tarefa de tentar definir termos psicopatológicos clássicos (tão desgastados pela história e diferentes traduções), como diversas obras anteriores, mas sim de transmitir os conceitos necessários para a adequada avaliação das vivências e manifestações psíquicas do ser humano. Para isso, seus 14 capítulos transitam livremente entre conceitos filosóficos, psicopatológicos e psicanalíticos para discorrer sobre alguns dos temas mais complexos e controversos da nossa prática clínica moderna. E é justamente este o segundo grande diferencial da presente obra, o de não só não se esquivar de situações clínicas limítrofes, mas de abordar áreas como a inter-relação e a frágil distinção entre criatividade e manifestações maníaco-depressivas (capítulo 1, uma valiosa contribuição do Professor Alfred Kraus), as implicações da categorização dos estados afetivos na criança (capítulo 2), e a estruturação da moral em jovens com desvios de conduta (capítulo 4). Dessa forma, demonstra que apenas integrando de forma plural e evolutiva a contribuição de autores de diferentes áreas do conhecimento é possível apreender (e compreender) o indivíduo em sua totalidade.

Dentro desta proposta de oferecer uma visão psicopatológica aplicada a situações clínicas, o livro procura ainda abordar a fenomenologia das crises não epilépticas psicogênicas e das transformações da personalidade associadas às epilepsias (capítulo 3), traz um interessante estudo de caso sobre um paciente portador de esquizofrenia paranóide sob a ótica fenomenológicaestrutural e da psicologia compreensiva de Jaspers (capítulo 6), e exemplifica como a psicopatologia fenômeno-estrutural contribui para o delineamento de um programa de terapia ocupacional em dois casos de demência (capítulo 8).

De particular interesse para a prática clínica, o capítulo 5 resgata o conceito de intuição, explorando as etapas do seu desenvolvimento, seu significado, e potencial valor diagnóstico e terapêutico no contato com o paciente. Também com um enfoque mais teórico (ainda que ilustrados, ou melhor, validados com casos clínicos), de forma a prover importantes ferramentas de refinamento psicopatológico ao leitor, os capítulos 7, 9, 10, 11, 12, 13 e 14 dedicam-se, respectivamente, à nosologia de Karl Jaspers, à espacialidade vivencial, aos aspectos fenomenológicos da interpessoalidade (em complemento ao capítulo 5), à possível relação entre linguagem e estrutura mental temporo-espacial (exemplificada através do estudo de um paciente com epilepsia do lobo temporal), à fenomenologia do desenvolvimento na infância, à biografia como método psicopatológico, e, por fim, ao uso da psicofarmacologia no contexto da psicopatologia fenomenológica.

Por apresentar uma abordagem inovadora da psicopatologia, propondo novos paradigmas adaptados à realidade clínica atual da psiquiatria, Psicopatologia Fenomenológica Contemporânea é uma importante contribuição teórica a todos os profissionais que atuam na área da saúde mental.

Marcus Vinicius Zanetti Departamento e Instituto de Psiquiatria, Faculdade de Medicina, Universidade de São Paulo (USP), São Paulo, Brasil

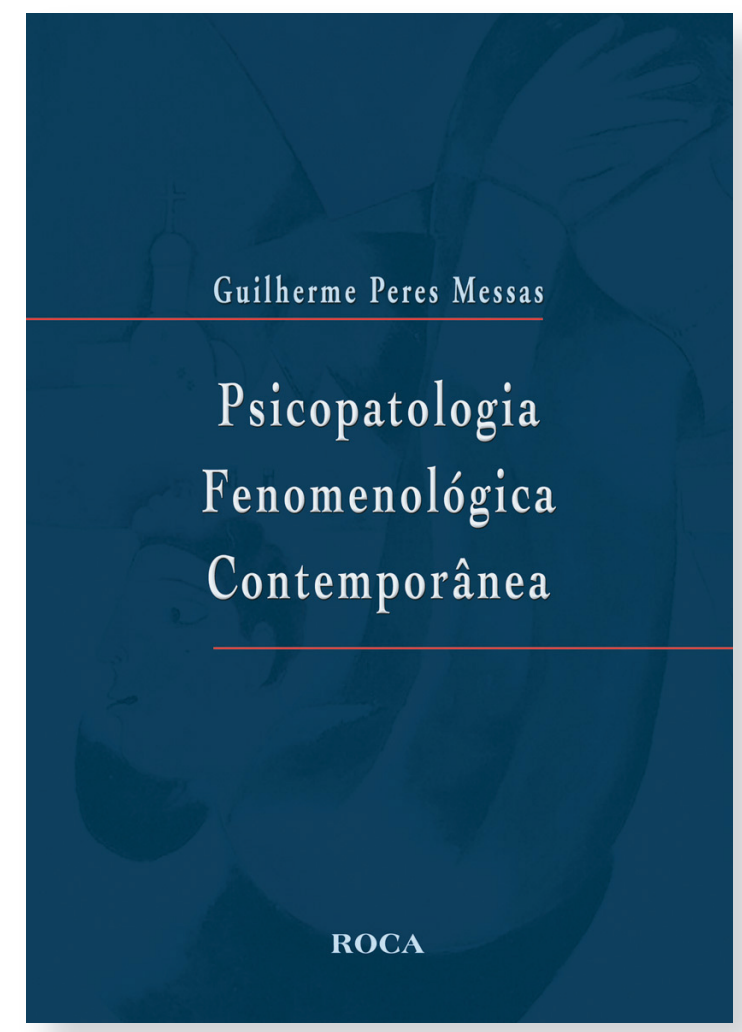

Referências

1. Ghaemi SN. The concepts of psychiatry: a pluralistic approach to the mind and mental illness. Baltimore (MD): Johns Hopkins University Press; 2003.

2. Andreasen NC. DSM and the death of phenomenology in America: an example of unintended consequences. Schizophr Bull. 2007;33(1):108-2. 